\title{
Whole genome sequences reveal multiple functions of PAT1 gene on environment adaptation and coat coloration in Tibetan sheep populations
}

Jianbin Liu ( $\nabla$ qmn@sippe.ac.cn )

Chinese Academy of Sciences https://orcid.org/0000-0003-2142-4024

\section{Xuezhi Ding}

Department of Animal Science

Chao Yuan

Department of Animal Science

Yufeng Zeng

Department of Animal Science

Tingting Guo

Department of Animal Science

Hao Zhang

Pizhou Agricultural and Rural Bureau of Jiangsu Province

Yaojing Yue

Department of Animal Science

Xilan Xu

Pizhou Animal Health Supervision Institute of Jiangnsu Province

Xiaoping Sun

Department of Animal Science

Chune Niu

Department of Animal Science

Bohui Yang

Department of Animal Science

Research article

Keywords: Tibetan sheep, altitude, cold tolerance, coat coloration

Posted Date: July 12th, 2019

DOI: https://doi.org/10.21203/rs.2.11247/v1 
License: (c) (i) This work is licensed under a Creative Commons Attribution 4.0 International License. Read Full License 


\section{Abstract}

Background: Most sheep breeding programs designed for the tropics and sub-tropics have to take into account the impacts of both productive and adaptive traits. However, the genetic mechanism regulating the multiple biological process remain unclear. Results: In this study, we report a novel PAT1 gene that simultaneously explained the variations of productive trait (coat color), adaptive traits (altitude and geography response) in 15 indigenous Tibetan sheep populations. Overlapped genomic regions harboring 6 candidate genes across three traits were identified at 27 chromosomes, with the top 1\% of Fst and $|Z \mathrm{ph}|$ values. The SNP/INDELs and expression of these candidate genes were further analyzed, and we find that only PAT1 gene, a CSDE1 homologue was consistent with the variation of multiple traits regarding. Haplotype analysis of PAT1 reveal that Tibetan sheep breeds with C-type of PAT1 have significantly greater body weight, shear amount, chest width and body length, but have lower body height, than those with CA-type of PAT1. Conclusions: We emphasized that PAT1 gene could be a potentially selective target used for the improvements of environmental adaption and coat coloration in the future. These results contribute to the knowledge of adaptive response in Tibetan sheep populations and will help to guide future conservation programs for Tibetan sheep native to Qinghai-Tibetan Plateau.

\section{Background}

Recent research data and model predictions indicate that increasing frequencies of abnormal weather events due to global climate change will have a fundamental impact on agricultural production [1]. For example, the livestock experiences numerous environmental stressors that have effects on both productive traits and adaptive traits, such as growth, reproductive performance, the meat quality and cold tolerance [2,3]. In particular, the influence of climate change - cold stress on living organisms is exacerbated at the interface of extreme environments that typically occurred in high altitude, plateaus and desert regions [4].

Designed breeding program for livestock should emphasize both productive traits and adaptive traits [5]. An interesting question arises here that except for cold environments adaptation, economic traits should be taken into account such as coat coloration. This is partially due to an intensive concern as to whether dark or light plumage is more effective in utilization of direct solar radiation since last century [6]. This phenomenon has been discussed on both theoretical and experimental bases [7]. For example, surface coloration arises from differential reflection or transmission of short wave radiation (the longest wavelength visually perceived by animals typically is near $700 \mathrm{~nm}$ ). This leads to animals with darkcolored pelages or plumages, and hence ostensibly greater absorptivity for short-wave radiation, acquire greater heat loads from solar radiation that do animals with light-colored coats [8-10]. The heat load on the skin from solar radiation is associated with index of coat color, body size and shape.

Tibetan sheep (Ovis aries) has ability to adapt to a wide range of agro-ecological conditions, it provides an excellent model to gain new insights into genetic mechanisms underlying the rapid adaptations of livestock to extreme environments [11-12]. This is also helpful to develop appropriate breeding programs 
under scenarios of future climate change. Tibetan sheep have lived on the Tibetan Plateau for thousands of years; however, the process and consequences of adaptation to this extreme environment conditions have not been elucidated [13]. This study is aimed to identify genes regulating environmental response and coat coloration in Tibetan sheep living in the Qinghai-Tibetan Plateau areas in China. Tibetan sheep representing different ecological regions in China and altitudes were used. Differentiated subpopulations were classified in respect of cold tolerance, geographic environments and coat coloration to uncover the casual genes incorporated with whole-genome sequencing. The key genes identified in this study would be helpful to guide breeding practices for improvements of both cold tolerance and coat coloration traits.

\section{Methods}

\section{Ethics statement}

All animals were handled according to the Guidelines for the Biological Studies Animal Care and Use Committee, People's Republic of China. Animal experiments were approved by the Animal Ethics Committee of the Institute of Animal Sciences of Chinese Academy of Agricultural Sciences.

\section{Physiological measurements of samples from different altitudes}

15 Chinese indigenous Tibetan sheep populations derived from different altitudes ranging from 3000$5000 \mathrm{~m}$ were used, where these samples were divided into two subgroups, high altitudes $(>4500 \mathrm{~m})$, and low altitudes ( $<3500 \mathrm{~m})$. 8 parameters related to body size: body weight/height/length, bust, chest depth, neck size, wool length, and shear amount; 13 physiological parameters: body temperature (Temperature), breathe rates (Breathe), pulse rates (Pulse), pulse interval (pulse interval), red-cell numbers (RBC), hematocrit, $\mathrm{HCT}$, erythrocyte mean corpuscular volume (MCV), mean corpuscular hemoglobin ( $\mathrm{MCH})$, Mean corpuscular hemoglobin concentration (MCHC), Hemoglobin (HGB), Platelet (PLT), Red blood cell volume distribution width coefficient variation (RGW-CV), White blood cell count (WBC). Biochemical parameters: Glutamic pyruvic transaminase (ALT), Glutamic pyruvic transaminase (AST), Total protein (TP), Albumin (ALB), Globulin (GLO), alkaline phosphatase (ALP), Lactate dehydrogenase (LDH), Cholinesterase (PCHE), Glucose (GLU), Total cholesterol (CHOL), Total calcium (CA); 9 blood-gas parameters: blood $\mathrm{pH}$, pressure $\mathrm{CO} 2$ ( $\mathrm{pCO} 2), \mathrm{O} 2$ saturation (O2S), concentration of $\mathrm{HCO} 3-$, standard bicarbonate, total CO2 concentration, Base Excess (BE), Standard Base Excess (SBE); structural parameters related to Lung tissue: bronchial, thin bronchial, end thin bronchial, alveolar numbers per area (AN/m2), thick alveolar interval (TAI).

\section{Sample collection and sequencing}

Ten milliliters of blood was collected from the jugular vein of each animal. From the $10 \mathrm{~mL}$ samples, 2 $\mathrm{mL}$ samples were quickly frozen in liquid nitrogen and stored at $-80^{\circ} \mathrm{C}$ for genomic DNA extraction, as described previously [14]. The total DNA was extracted from the blood using the saturated salt method and adjusted to $50 \mathrm{ng} / \mu \mathrm{L}$ [15]. The blood were sampled from 636 Tibetan sheep in the Qinghai-Tibetan Plateau region in China as mentioned previously [16]. The detailed sampling information for the 15 
indigenous Tibetan sheep populations, i.e., population code, sample number, altitude, longitude and latitude, sampling location, and geographical location, is shown in Table 1. For each Tibetan sheep, genomic DNA was extracted from $200 \mu \mathrm{L}$ of peripheral venous blood using the QIAamp DNA blood mini kit (Qiagen, Germany) as described previously [17]. Briefly, A260/280 ratio and agarose gel electrophoresis were used to evaluate the quality and integrity of the DNA. Genomic DNA was masked to a 300-400bp fragment for library preparation, followed by end repair and ligated with an Illumina sequencing linker. The ligated products with sizes of $400-500 \mathrm{bp}$ were loaded on $2 \%$ agarose gels and subsequently amplified via PCR. Libraries were sequenced by HiSeq 2500 sequencer (Illumina) in a $2 \times$ 100 bp paired end mode.

\section{Reads alignment and variations calling}

Reads were aligned to the sheep reference genome Ovis 3.1

(https://www.ncbi.nlm.nih.gov/genome/genomes/83) using BWA (0.6.2-r126 version) followed by duplicate removal using Picard-Tools-1.55 (http://broadinstitute. github.io/picard/). The Genome Analysis Toolkit (GATK-2.6) was used to perform local realignment around existing INDELs and base quality score recalibration. Variant detection was performed using the GATK Unified Genotyper. To filter SNPs for flowing analysis, at least three reads with different start sites supporting the non-reference allele had to be present.

\section{Classification of types from SNP/INDEL variants}

The 15 indigenous Tibetan sheep populations living in the Qinghai-Tibetan Plateau areas in China were classified into different subpopulations to estimate the candidate genes (Table 2). According to originated altitude information, two subpopulations were divided, i.e., lowland Tibetan sheep ( 3500m): GD, QL, TJ, QH, MX, GJ, QK, and GN; highland Tibetan sheep (>4500m): LKZ, JZ, GB, HB, DM, AW, and LZ. In terms of coat coloration types, black coat coloration includes $M X$ and GD, whereas white coat coloration includes QL, TJ, QH, GJ, QK, GN, LKZ, JZ, GB, HB, DM, AW, and LZ. For geographic regions, three different provinces in China were classified, Qinghai (QH, GD, QL, and TJ); Gansu (MX, GJ, QK, and GN); Titeban (LKZ, JZ, GB, HB, DM, AW and LZ).

\section{Population genetics analysis}

The pairwise genetic distance was determined relying on the number of allelic differences as described previously [17]. Briefly, the neighbor join tree was calculated based on the distance matrix Using PHYLIP (version 3.69) [18]. SNP pair with high correlation were removed via PLINK (PLINK, RRID: SCR 001757) [19]. The PCA and population structure were performed using EIGEN-SOFT (version 6.0.1) and FRAPPE software (version 1.1), respectively [20,21]. As previously mentioned, TreeMix was applied to estimate migration events, with migration numbers $m=0-5$ [22]. The selective sweep analysis was performed

using VCFtools, $v 0.1 .12 b$ [23], including $\theta$ (number of isolated sites), $\pi$ (paired nucleotide difference), and Tajima's D. There are 500,000 SNPs randomly selected from the genome, and these SNPs were used to analyze the linkage disequilibrium 12 with Haploview [24]. 


\section{Genome-wide Selective Sweep Test}

We calculated the genome-wide distribution of Fst values as previous reports in [25] for three subpopulation pairs as mentioned above as to originated altitude information, coat coloration types, and geographic regions (Table 2), using a sliding-window approach (100-kb windows with 50-kb increments). To identify regions that were likely to be or have been under selection, the " $Z$ transformed heterozygosity" $(Z H p)$ approach was used, as previously described [26]. Individual $H p$ values were $Z$ transformed as follows: $Z H p=(H p-\mu H p) / \sigma H p$, where $\mu H p$ is the overall average heterozygosity, and $\sigma H p$ is the standard deviation for all windows within each population. We calculated the $Z H p$ value in sliding $150-k b$ windows along the autosomes from sequence reads corresponding to the most and least frequently observed alleles at all SNP positions as previously described [27].

\section{Bioinformatics analysis of breed specific SNPs/INDELs}

Overlapped candidate genes across originated altitudes, coat coloration, and ecological regions were chosen for further analysis. In addition to this, we compared gene sequence of Capra hircus, Pantholops hodgsonii, and Bos taurus from NCBI database (https://www.ncbi.nlm.nih.gov/genome). We specifically focused on SNPs within genes and 1000-bp upstream and downstream flanking regions. Protein-protein interaction network was used to compare potential interactive genes with key overlapped genes in Homo sapiens from STRING database [28].

\section{Validation of interactive genes}

Expression of putative proteins interacted with key overlapped candidates relating to genetic variation of originated altitudes, coat coloration, and ecological regions as mentioned above were confirmed by qPCR. Detailed procedures for real-time PCR amplification were performed following standard protocol of SYBR Green real-time PCR kit (Applied Biosystems ${ }^{\text {TM }}$ SYBR $^{\text {TM }}$ Green). The primer is listed in Supplementary Table $S 1 . \beta$-actin gene was used as internal control. The levels of relative gene expression were calculated against the expression of RXFP2 [17], using 2-Ct method [29]. Four biological replicates and three technical replicates were conducted.

\section{Results}

\section{Genomic sequencing and PCA in 15 in indigenous Tibetan sheep populations}

In this study, we aim to identify the candidate genes that explain the variations of both productive and adaptive traits. To accomplish this, we sequenced 15 indigenous Tibetan sheep populations originated from different altitudes (Table 1), via high-resolution whole genomic sequences techniques (WGS). To dissect the genomic heterozygosity levels and recombination events, we classified these 15 indigenous Tibetan sheep populations into different subpopulations, including high altitude hypoxia $(>4500 \mathrm{~m})$ vs. low altitude hypoxia $(<3500 \mathrm{~m})$, white vs. black coat coloration, and three different geography locations, i.e., Qinghai, Gansu, and Tibetan (Table 2). WGS was performed on an Illumina HiSeq 2000 platform by 
using the pooled DNA from each population. Genome sequencing yielded a total of $214 \mathrm{~Gb}$ raw data, and produced 230 to 310 million sequence reads per population (Table S2). Over $97.50 \%$ of the generated sequence reads mapped to approximately $94.15 \%$ (87.42-98.53\%) of the newly annotated Tibetan sheep reference genome (Ovis 3.1), indicating that high quality sequences were obtained (Table S3). Our efforts yielded an average sequence coverage of $10.3 \times$ per population, within a range of $9 \sim 14$ fold. Singlenucleotide polymorphisms (SNPs) varied from 2-4 million for each population (Table S3-S4).

More than 9 million SNPs for each Tibetan sheep population that confidently remained after filtering were used in the subsequent analyses. Results from SNPs statistics showed that $63 \%$ SNPs were identified at intergenic regions, whereas only $0.7 \%$ SNPs cases were found at exon regions (Table S5). Principal components analysis (PCA) was performed to examine the genetic separation of 15 indigenous Tibetan sheep populations originated spanning in the Qinghai-Tibetan Plateau areas in China (Fig. 1A). PCA results clearly showed that most Tibetan sheep have high genetic homogeneity except Minxian Black Fur sheep (MX) and Jiangzi sheep (JZ) (Fig. 1B). After calling SNP, we obtained 9.3 million SNPs across those Tibetan sheep populations. The distribution of minor allelic frequency (MAF) with 10 continued classes from 0-0.05 to 0.45-0.50 for each population was observed (Fig. 1C). MAF of SNPs across 15 indigenous Tibetan sheep populations showed MAF within the range of $0 \otimes 5 \%$ had most relative abundance with around $20 \%$ of total SNPs, whereas $5 \rrbracket 15 \%$ MAF showed relatively low abundance with less than $3 \%$ across 15 indigenous Tibetan sheep populations. The distribution pattern of MAF among Tibetan sheep populations was similar except for LKZ (Fig. 1C). Similarity index (IS) value was used to estimate the homogeneity of SNPs across 15 indigenous Tibetan sheep populations. LKZ showed lowest similarity with other Tibetan sheep populations, which is consistent with MAF distribution results (Fig. 1D).

\section{Overlapped selective signals regarding genomic heterozygosity among productive and adaptive traits}

Fst values over the whole genome based on genetic differentiation in different Tibetan sheep populations were classified by altitude hypoxia (altitude), coat coloration (color), and geography locations, named geography. Some overlapped genes were identified with high Fst values, including ZEB, RALY, 1L12RB1, $A S I P$, and ARAP1 (Fig. 2A-C; Table S6). Results showed that 31, 1, and 22 common genes were identified that in classifications of altitude \& geography, color \& altitude, and color \& geography, respectively (Fig. 2D).

In addition, we found other 5 genes, except IL12RB1 at chr. 5 which was identified in both coat coloration and geography. Among these genes we cite; CSF2, LOC106990309 that specifically in Tibetan geography locations, TRNAC-GCA, ACSL 6 and MEIKIN were specifically in white coat coloration subpopulations (Figure S1; Table S6). At chr.15, another 11 genes, except ARAP1 mainly related to coat coloration and geography clusters, were identified with high Fst values, including LOC101104426, LOC101105946, LOC101104685, LOC101106201, LOC101104933, LOC101106712, LOC101105186, LOC101104177, LOC101105439, LOC101106459, and LOC101105686 (Figure 2E; Table S6). These genes also showed high heterozygosity levels specifically to Tibetan geography locations and white coat coloration 
populations (Figure S1 and S3). We found 4 genes in chr.18 including CRYBB3, ADRBK2, KIAA1671, and $C R Y B B 2$ (Figure 2E). These genes have high heterozygosity specifically in Tibetan geography locations (Figure S3). At chr.23, there are two genes, PSMA8 and TAF4B, possessing high Fst values as well as high heterozygosity levels, which are identified uniquely in low altitude subpopulations (Figure S2; Table S6). In addition, there are 7 genes at chr.27 with high Fst values and heterozygosity in low altitude subpopulations, including LOC105605498, ITGB1BP2, LOC105605499, LOC101104554, GJB1, ZMYM3 and NONO (Table S6).

Moreover, we also identified 13 novel genes at chr.13 with high Fst values that identified in both altitude and geography locations, including ZEB1, PANK2, RNF24, LOC101110166, VPS16, PCED1A, PTPRA, TMEM239, C12H20, LOC101113781, CPXM1, LOC105606248 and EBF4. Among these genes, ZEB1 has high heterozygosity specifically in low altitude subpopulations; however, PANK2, RNF24, LOC101110166, VPS16, PCED1A, PTPRA are specifically in Tibetan geography subpopulations with high heterozygosity, while TMEM239, C12H20, LOC101113781, CPXM1, LOC105606248 and EBF4 are specifically in white coat coloration subpopulation (Table S6). These results suggested that these overlapped genes identified in both altitude and geography locations are related to convergent adaption to high altitudes in indigenous sheep breeds.

Notably, among three defined clusters, i.e., cold, color and environments, there are 6 common genes that have been identified simultaneously. These genes are located at chromosome 27 . These genes include PAT1 (LOC101123097, also named productive and adaptive traits), KLF4, PSMA1, POF1B, APOOL, and ZNF711 (Table S6). These genes have high heterozygosity levels within either white coat coloration or low altitude subgroups (Table S6).

\section{Haplotypes of PAT1 are related to adaptive response to environments and body size}

To further analyze the natural variations of these 6 overlapped genes, we analyzed INDELs of these genes including $2 \mathrm{k}$-bp promoter and CDS regions along with other species, such as Capra, Pantholops, and Bos Taurus (Figure 3). Results from INDEL information showed that $62 \%$ INDEL events were identified at intergenic regions, whereas only $0.3 \%$ INDEL cases were found at exon regions (Table S7). Our findings suggested that among 6 genes, only INDEL at 5'-flank region of PAT1 can fully explain the variations of different defined clusters in altitude variations, coat color, and geography locations. C-type is occurred in high altitude, black coat coloration, and Gansu geography location, while CA-type is occurred in low altitude, white coat coloration, and both Qinghai and Tibetan geography regions (Figure S1-S3).

We further analyzed the protein structure and gene expression pattern among different indigenous Tibetan sheep populations (Figure 4). According to bioinformatics analysis, we predicted the protein sequences of PAT1 according to translate tool in ExPASy database (https://web.expasy.org/translate/), and found the similarities score is $99 \%$ in both mRNA and protein sequences between CSDE1 and PAT1 protein, indicating its counterpart roles of PAT1 with CSDE1. We predicted the secondary structure of PAT1 with 798 amino acids, and found there are 13 different amino acids. Most variation loci were observed at $\mathrm{N}$-terminal of protein containing 7 different amino acids, and these amino acids were located 
in either Beta strand or Turn domains, but not Helix (Figure 4A). Three different amino acids were mapped at 3D protein structure from two PDB entries (1WFQ and 2YTX) according to Uniprot database (CSDE1_Human Protein ID: 075534).

To compare the expression between PAT and CSDE1, we used 6 indigenous Tibetan sheep populations, including Guide Black Fur sheep (GD), Qilian White Tibetan sheep (QL), Minxian Black Fur sheep (MX), Ganjia Tibetan sheep (GJ), Huoba Tibetan sheep (HB) and Awang Tibetan sheep (AW). These Tibetan sheep can be classified into different populations regarding altitude, coat coloration and geography locations. We found PAT1 gene is highly expressed in high altitude, black coat coloration subpopulations, rather than low altitude and white coat coloration subpopulations. PAT1 gene also performed distinct pattern among different geography locations (Figure 4C). CSDE1 gene exhibited similar pattern with PAT1 across different Tibetan sheep populations, except in QL which showing high expression of PAT1, but is a white coat coloration sheep (Figure 4D). Therefore, an interesting question arising here is whether interactive proteins with CSDE1 could show similar expression pattern between the subpopulations of altitude, color and geography region? Therefore, we reconstructed the protein-protein interaction networks using CSDE1, and found PABPC1 and $M Y C$, with relatively high correlation with PAT1, bears similar expression pattern with PAT1 (Figure S4).

To interpret the biological functions of PAT1, we compared 47 physiological and biochemical parameters in representative 4 indigenous Tibetan sheep populations with different promoter haplotypes of PAT1 gene (Figure 5; Table 2). As mentioned in Figure 3C, there are two haplotypes, C-type and CA-type, containing AW\&HB, and GJ \& QL Tibetan sheep populations, belong to both high and low altitude clusters, respectively. Tibetan sheep subpopulations with C-type of PAT1 have significantly greater body weight, shear amount, chest width and body length, but have low body height, relative to sheep in subgroups with CA-type of PAT1 (Figure 5A-B).

\section{Discussion}

Global climate change would have a fundamental impact on agricultural production. Integrated characteristic for livestock needs to be taken in consideration for designed breeding program, including adaptive ability to high altitudes, black coat coloration, and widespread geographical locations. Tibetan sheep is known to adapt to various agro-ecological conditions, it therefore represents an excellent model for understanding genetic mechanisms on adaptations of livestock to extreme environmental conditions. This study is aimed to identify key genes those regulate environmental response and coat coloration simultaneously.

\section{Overlapped genes in the explanation of altitude and geography variations}

It is common that hypoxia-inducible factors (HIFs) are transcription factors that respond to changes in the available oxygen in the cellular environment under high-altitude conditions. In this study, we identified a candidate gene, ZEB1 at chr.13 with top 1\% Fst values in both altitude and geography variations (Figure 
$2 \mathrm{~A}-\mathrm{C})$. It is reported that ZEB1 is a target gene of HIFs, which is critical in the regulation of the macrovascular angiogenic response but not that of microvascular angiogenesis [32]. Moreover, under hypoxic conditions, HIF-1a up-regulates the expression of proteins that induce TWIST1 and ZEB1 [33,34]. $R A L Y$ is identified to be correlated with both altitude and geography variations, which has been reported as candidate genes with significant enrichments in spliceosomal complex pathway in high-altitude adaption Tibetan sheep populations, indicating its important roles in hypoxia response [13]. Fst values, also named fixation index, were typically used to evaluate differentiated genomic regions and identify selective signals among whole-genomic SNPs [30,31]. IL 12RB1 is identified with high Fst values for both color and geography (Figure $2 \mathrm{~B}-\mathrm{C}$ ), and IL12RB1 also has high levels of heterozygosity specifically in Tibetan geography locations (Figure S3). The numbers of totally overlapped candidate genes were presented based on top 1\% Fst values for different combinations among altitude, color and geography from 150-kb windows (Figure 2D).

\section{Overlapped genes in the explanation of coat coloration and geography variations}

Differentiated genomic regions in classification of geography factor reflect environmental selections and robustness. We identified that two known genes that is related to variation of both geography and coat coloration. ARAP1 gene at chr.15 has been previously reported to be under climate-driven selection as signal molecular involving in GTPase regulator activity process [35], which is in charge of various types of membrane transport, such as vesicle fusion and docking of transport vesicles to specific target organelles and/or plasma membranes during secretory processes [36,37]. It can anchor and transport melanosomes to the plasma membrane, and melanosomes within melanocytes is critical for pigmentation synthesis of hair [38]. IL12RB1 at chr.5, was also correlated with environmental selection [35]. It is involved in cytokine-cytokine receptor interaction pathways, and cytokine is secreted by keratinocytes and by melanocytes during the first two steps of Hyperpigmentation in the epidermis [39]. We also compared levels of genomic heterozygosity within different subpopulations as represented by IZHp| values [40], and found IL12RB1 has high levels of heterozygosity specifically in Tibetan geography locations (Figure S3).

\section{Coat coloration, altitude and geography variations}

Our findings suggested that only variation of SNP/INDEL at 5'-flank region of PAT1 can fully explain the phenotypic variations in combined characteristics of altitude response, coat color, and geography locations (Figure $3 \mathrm{C}$ ). This indicates that the expression of this gene could play key roles in regulating these productive and adaptive traits, which would be discussed in the following. For other genes, the INDEL variation only can explain partially to defined clusters. For example, the KLF4 has 4 types of INDELs, in 5'flank and other 3 intron regions. The types of INDEL can explain the variation of altitudes and coat coloration, but not three geography types. PSMA1 can explain coat coloration variation but cannot explain variation of other two clusters, whereas ZNF711 can explain altitude variation, but cannot explain variation of another two clusters. Taken together, only the 5'-UTR of PAT1 can largely explain the 
variance of three classifications, indicating that genetic basis of such as coat coloration and adaptive traits relies on gene expression.

\section{Function of PAT1 in productive and adaptive characteristics}

The CSDE1 (Cold Shock Domain Containing E1), alternative name: UNR, is a conserved RBP containing five cold-shock domains (CSDs) that bind single-stranded RNA [41, 42]. We confirmed CSDE1 homologous protein, PAT1 showed clear differences between high low altitudes subpopulation of Tibetan sheep populations and between different geography locations with changed climate conditions (Figure 3C). CSDs represent the most evolutionarily conserved nucleic acid-binding protein domain, found in bacteria and eukaryotes $[43,44]$. This domain of around 70 amino acid residues mediates binding to single-stranded DNA and RNA [45, 46]. Function of proteins possessing CSDs are involved in two processes: transcriptional and translational control. Two major old shock proteins CspA and CspB in Escherichia coli and Bacillus subtilis, respectively, were intensively reported. CspA and CspB are massively and transiently induced after a temperature downshift and are involved in the adaptation to cold shock [47].

To explain the relationship of PAT1 and CSDE1 with coat coloration, we reconstructed the CSDE1centerized module according to STRING protein-interaction database, and we found 9 genes that involving in this module. These are: MAX, MYC, YBX1, HNRNPU, DHX9, PABPC1, PAIP1, STRAP, SYNCRIP. Differential gene expression analysis via qPCR suggested that these genes have strong correlation with CSDE1 and PAT1 (Table S8). Previous reports showed that CSDE1 mRNA is up-regulated in a high percentage of skin and ovary cancers, and UNR/CSDE1 regulates critical Melanoma genes, including $P A B P C 1$ gene [48]. Beside, CSDE1 regulates internal ribosome entry site (IRES)-dependent translation of the transcripts encoding the oncogene MYC [49]. The both PABPC1 and MYC were identified in CSDE1interative protein network (Figure S4), and we confirmed that expression of the two genes showed distinct pattern between white coat coloration and black coat coloration subpopulations, especially for PABPC1 (Figure S4C). These inherent correlations probably explain the variation of coat coloration regulated by CSDE1/PAT1.

\section{Morphological and physiological parameters of different haplotypes}

Different haplotypes of PAT1 could be reflective of altitude response, and is related to changes of morphological characters, such as body weight, shear amount, chest width and body length and body height (Figure 5A-B). This is consistent with the conclusion that large physical size in highland as observed in man [50]. In particular, body weight of Tibetan sheep in C-type population is 1.7 times higher than that in CA-type group. For body haematological parameters, body temperature, pulse interval, $\mathrm{MCH}$, MCHC, HGB levels are at least 1.5 times higher in C-type of PAT1 group than that in CA-type population; this is similar to that observed in Tibetan sheep and dogs $[13,51]$. Interestingly, breathe rates, pulse rates, RBC, HCT, MCV, PLT, and RDW-CV are relatively lower in C-type of PAT1 than that in CA-type population. Values of blood-gas parameters were similar or relatively lower in C-type population than that in CA-type population, except for p02. For lung tissue structure parameters, values are relatively higher in C-type 
population than that in CA-type population. In particular, elevated lactate dehydrogenase (LDH) in C-type population relative to CA-type population support the found in other sheep studies on hypoxemia response [52].

\section{Conclusion}

Dissection of casual genes and molecular mechanism responsible for high altitude and coat coloration in this study is pivotal in Tibetan sheep objective breeding towards improvements of productive and adaptive traits. We identified a CSDE1 like gene, named PAT1, variation of INDEL at chr 27: 72792241 within 5'-UTR explain the genetic diversity and phenotypic classification in given 15 indigenous Tibetan sheep populations. We highlight that the importance of PAT1 in future Tibetan sheep breeding program for environmental adaptation and coat economics.

\section{Abbreviations}

PAT: productive and adaptive traits; Temperature: body temperature; Breathe: breathe rates; Pulse: pulse rates; pulse interval: pulse interval; RBC: red-cell numbers; $\mathrm{HCT}$ : hematocrit; $\mathrm{MCV}$ : erythrocyte mean corpuscular volume; $\mathrm{MCH}$ : mean corpuscular hemoglobin; MCHC: Mean corpuscular hemoglobin concentration; HGB: Hemoglobin; PLT: Platelet; RGW-CV: Red blood cell volume distribution width coefficient variation; WBC: White blood cell count; ALT; Glutamic pyruvic transaminase; AST: Glutamic pyruvic transaminase; TP: Total protein; ALB: Albumin; GLO: Globulin; ALP: alkaline phosphatase; LDH: Lactate dehydrogenase; PCHE: Cholinesterase; GLU: Glucose; CHOL: Total cholesterol; CA: Total calcium; pC02: pressure CO2; O2S: 02 saturation; BE: Base Excess; SBE: Standard Base Excess; AN/m2: end thin bronchial, alveolar numbers per area; TAl: thick alveolar interval; Guide Black Fur sheep: GD; Qilian White Tibetan sheep: QL; Tianjun White Tibetan sheep: TJ; Qinghai Oula Tibetan sheep: QH; Minxian Black Fur sheep: MX; Ganjia Tibetan sheep: GJ; Qiaoke Tibetan sheep: QK; Gannan Oula Tibetan sheep: GN; Langkazi Tibetan sheep: LKZ; Jiangzi Tibetan sheep: JZ; Gangba Tibetan sheep: GB; Huoba Tibetan sheep: HB; Duoma Tibetan sheep: DM; Awang Tibetan sheep: AW; Linzhou Tibetan sheep: LZ; MAF: minor allelic frequency; HIFs: hypoxia-inducible factors; CSDE1: Cold Shock Domain Containing E1; CSDs: coldshock domains.

\section{Declarations}

\section{Ethics approval and consent to participate:}

All animals were handled according to the Guidelines for the Biological Studies Animal Care and Use Committee, People's Republic of China. Animal experiments were approved by the Animal Ethics Committee of the Institute of Animal Sciences of Chinese Academy of Agricultural Sciences.

\section{Declarations}


Consent for publication:

Not applicable.

\section{Declarations}

\section{Availability of data and material:}

The datasets used and/or analyzed during the current study are available from the corresponding author on reasonable request.

\section{Declarations}

\section{Competing interests:}

The authors declare that they do not have any competing interests

\section{Declarations}

\section{Funding:}

This work was supported by the National Natural Science Foundation for General Program of China (Grant No. 31872981), the National Key Research and Development Program of China (Grant No. 2018YFD050203), the Agricultural Science and Technology Innovation Program of China (Grant no. CAAS-ASTIP-2015-LIHPS), the Modern China Wool Cashmere Technology Research System (Grant no. CARS-39-02), the Key Research and Development Program of Gansu Provincial-Agricultural Project (Grant no. 17YF1NA069), the Modern Agricultural Technology Research System of Gansu (Grant no. GARS08)】 and the Central Level of Scientific Research Institutes for Basic R \& D Special Fund Business (Grant no. 1610322015002).

\section{Declarations}

\section{Authors' contributions:}

Conceived and designed the experiments: LJB DXZ ZYF YC. Performed the experiments: LJB DXZ SXP NCE. Analyzed the data: ZYF YC GTT. Wrote the paper: LJB YBH.

\section{Declarations}

\section{Acknowledgements:}

We thank Shanghai Orizymes Biotech. Co., Ltd, for whole-genome sequencing services and bioinformatics support.

\section{References}


1. Bernstein L, Bosch P, Canziani O. IPCC, 2007: Climate Change 2007: Synthesis Report. Contribution of Working Groups I, II and III to the Fourth Assessment Report of the Intergovernmental Panel on Climate Change. Intergovernmental Panel on Climate Change, Geneva.

2. Brown ME, Funk CC. Food security under climate change. Science. 2008; 319:580-581.

3. Hoffmann I. Climate change in context: implications for livestock production and diversity. In: Odongo $\mathrm{NE}$, Garcia M, Viljoen GJ, editors. Sustainable improvement of animal production and health. Vienna: IAEA-FAO. 2010: 33-44.

4. Easterling DR, Meehl GA, Parmesan C, Changnon S, Karl TR, Mearns LO. Climate extremes: observations, modeling, and impacts. Science. 2000; 289: 2068-2074

5. König EZ, Mirkena T, Strandberg E, Audho J, Ojango J, Malmfors B, Okeyo AM, Philipsson J. Participatory definition of breeding objectives for sheep breeds under pastoral systems-the case of Red Maasai and Dorper sheep in Kenya. Trop Anim Health Prod. 2016; 48: 9-20.

6. Lustick S, Adams M, Hinko A. Interaction between posture, color, and the radiative heat load in birds. Science. 1980; 208: 1052-1053.

7. Walsberg GE, Campbell GS, King JR. Animal coat color and radiative heat gain: a re-evaluation. J. Comp. Physiol. 1978; 126: 211-222.

8. Hamilton WJ, III. Life's color code. McGraw-Hill, New York. 1973; pp 214-221.

9. Lustick S. Plumage color and energetics. Condor. 1971; 73: 121-222.

10. Lustick S, Battersby B, Kelty M. Behavioral thermoregulation: orientation toward the sun in Herring Gulls. Science. 1978; 200: 81-83.

11. Howden SM, Soussana JF, Tubiello FN, Chhetri N. Adapting agriculture to climate change. Proc Natl Acad Sci USA. 2007; 104:19691-19696.

12. Lobell DB, Burke MB, Tebaldi C, Mastrandrea MD, Falcon WP, Naylor RL. Prioritizing climate change adaptation needs for food security in 2030. Science. 2008; 319: 607-610.

13. Wei C, Wang H, Liu G, Zhao F, Kijas JW, Ma Y, Lu J, et al. Genome-wide analysis reveals adaptation to high altitudes in Tibetan sheep. Sci Rep. 2016; 6: 2677-2681.

14. D'Angelo F, Ciani E, Sevi A, Albenzio M, Ciampolini R, Cianci D. The genetic variability of the Podolica cattle breed from the Gargano area. Preliminary results. Ital J Anim Sci. 2006; 5: 79-85.

15. Sambrook J, Russell DW. Molecular cloning: A laboratory manual. 3rd ed. New York: Cold Spring Harbor Laboratory Press; 2001. 
16. Liu J, Ding X, Zeng Y, Yue Y, Guo X, Guo T, Chu M, et al. Genetic diversity and phylogenetic evolution of Tibetan Sheep based on mtDNA D-Loop sequences. PloS one. 2016;11(7):e0159308.

17. Pan ZY, Li SD, Liu QY, Wang Z, Zhou ZK, Di R, Miao BP, Hu WP, Wang XY, Hu XX, Xu Z. Whole-genome sequences of 89 Chinese sheep suggest role of RXFP2 in the development of unique horn phenotype as response to semi-feralization. Gigascience. 2018; 24: 42-47.

18. Felsenstein, J. PHYLIP - Phylogeny Inference Package (version 3.2). Cladistics. 1989; 5:164-6.

19. Sabeti PC, Varilly P, Fry B, Lohmueller J, Hostetter E, Cotsapas C, Xie X, Byrne EH, et al. Genome-wide detection and characterization of positive selection in human populations. Nature. 2007; 449: 913-8.

20. Patterson N, Price AL, Reich D. Population structure and eigen analysis. PLoS Genet, 2006; 2: 207493.

21. Tang $\mathrm{H}$, Peng J, Wang P, Risch NJ. Estimation of individual admixture: analytical and study design considerations. Genet Epidemiol. 2005; 28: 289-301.

22. Pickrell JK, Pritchard JK. Inference of population splits and mixtures from genome-wide allele frequency data. PLoS Genet, 2012; 8(11):e1002967. doi:10.1371/journal.pgen. 1002967.

23. Danecek P. Auton A, Abecasis G, Albers CA, Banks E, DePristo MA, et al. The variant call format and VCFtools. Bioinformatics. 2001; 27: 2156-8.

24. Barrett JC, Fry B, Maller J, Daly MJ. Haploview: analysis and visualization of LD and haplotype maps. Bioinformatics, 2005; 21:263-5.

25. Weir BS, Cockerham CC. Estimating F-statistics for the analysis of population structure. Evolution. 1984; 38: 1358-1370, doi: 10.2307/2408641.

26. Rubin CJ, Megens HJ, Martinez Barrio A, Maqbool K, Sayyab S, Schwochow D, Wang C, Carlborg Ö, Jern P, Jørgensen CB, Archibald AL, Fredholm M, Groenen MA, Andersson L. Strong signatures of selection in the domestic pig genome. PNAS. 2012; 109: 19529-19536.

27. Rubin CJ, Zody MC, Eriksson J, Meadows JRS, Sherwood E, Webster MT, Jiang L, et al.. Wholegenome resequencing reveals loci under selection during chicken domestication. Nature. 2010; 464: 587591

28. Von Mering, C. Jensen LJ, Snel B, Hooper SD, Krupp M, Foglierini M, Jouffre N, Huynen MA, Bork P. String: known and predicted protein-protein associations, integrated and transferred across organisms. Nucleic acids research 2005; 33: 433-437.

29. Livak KJ, Schmittgen TD. Analysis of relative gene expression data using real-time quantitative PCR and the 2(T)(-Delta Delta C) method. Methods, 2001; 25: 402-8. 
30. Weir BS, Cockerham CC. Estimating F-statistics for the analysis of population structure. Evolution. 1984; 38: 1358-1370, doi: 10.2307/2408641.

31. Akey JM, Ruhe AL, Akey DT, Wong AK, Connelly CF, Madeoy J, Nicholas TJ, Neff MW. Tracking footprints of artificial selection in the dog genome. PNAS. 2010; 107: 1160-1165.

32. Luo Z, Wen G, Wang G, Pu X, Ye S, Xu Q, Wang W, Xiao Q. MicroRNA-and play an important role in endothelial cell differentiation and vasculo genesis by targeting transcription repressor ZEB1. Stem Cells. 2013; 31: 1749-1762.

33. Martin A, Cano A. Tumorigenesis: twist links EMT to self-renewal. Nat Cell Biol. 2010; 12: 924-925.

34. Semenza GL, Nejfelt MK, Chi SM, Antonarakis SE. Hypoxia-inducible nuclear factors bind to an enhancer element located 3 ' to the human erythropoietin gene. P Natl Acad Sci. USA. 1991; 88: 56805684 .

35. Lv FH, Agha S, Kantanen J, Colli L, Stucki S, Kijas JW, Joost S, Li MH, Ajmone Marsan P. Adaptations to climate-mediated selective pressures in Sheep. Mol. Biol. Evol., 2014; 31: 3324-43

36. Fukuda M. Regulation of secretory vesicle traffic by Rab small GTPases. Cell Mol Life Sci. 2008; 65: 2801-2813.

37. Stenmark H. Rab GTPases as coordinators of vesicle traffic. Nat Rev Mol Cell Biol. 2009; 10: 513525.

38. Steingrímsson E, Copeland NG, Jenkins NA. Mouse coat color mutations: From fancy mice to functional genomics. Dev Dyn. 2006; 235: 2401-2411.

39. Murase D, Hachiya A, Amano Y, Ohuchi A, Kitahara T, Takema Y. The essential role of p53 in hyperpigmentation of the skin via regulation of paracrine melanogenic cytokine receptor signaling. J. Bio. Chem. 2009; 284: 4343-4353.

40. Bryc K, Patterson N, Reich D. A novel approach to estimating heterozygosity from low-coverage genome sequence. Genetics. 2013; 195: 553-561.

41. Goroncy AK, Koshiba S, Tochio N, Tomizawa T, Inoue M, Watanabe S, Harada T, Tanaka A, Ohara O, Kigawa T, Yokoyama S. The NMR solution structures of the five constituent cold-shock domains (CSD) of the human UNR (upstream of N-ras) protein. J. Struct. Funct. Genomics. 2010;11, 181-188.

42. Triqueneaux G, Velten M, Franzon P, Dautry F, Jacquemin-Sablon H. RNA binding specificity of Unr, a protein with five cold shock domains. Nucleic Acids Res. 1999; 27, 1926-1934.

43. Graumann P, Wendrich TM, Weber MH, Schröder K, Marahiel MA. A family of cold shock proteins in Bacillus subtilis is essential for cellular growth and for efficient protein synthesis at optimal and low 
temperature, Mol. Microbiol, 1997; 25: 741-756.

44. Graumann P, Mahariel MA. A case of convergent evolution of nucleic acid binding modules. Bioessays, 1996; 18: 309-315.

45. Wolffe AP. Structural and functional properties of the evolutionary ancient Y-box family of nucleic acid binding proteins. BioEssay. 1994; 16: 245-251.

46. Sommerville J, Ladomery M. Transcription and masking of mRNA in germ cells: involvement of Y-box proteins, FASEB J. 1996; 10: 435-443.

47. Thieringer HA, Jones PG, Inouye M. Cold shock and adaptation. Bioessay, 1998; 20: 49-57.

48. Wurth L, Papasaikas P, Olmeda D, Bley N, Calvo GT, Guerrero S, et al. UNR/CSDE1 drives a posttranscriptional program to promote melanoma invasion and metastasis. Cancer Cell, 2016; 30: 694-707.

49. Evans JR, Mitchell SA, Spriggs KA, Ostrowski J, Bomsztyk K, Ostarek D, Willis AE. Members of the poly $(\mathrm{rC})$ binding protein family stimulate the activity of the c-myc internal ribosome entry segment in vitro and in vivo. Oncogene. 2003; 22: 8012-8020.

50. Lenfant, C. High altitude adaptation in mammals. Amer. Zool., 1973; 13: 447-456.

51. Gou X. Gou X, Wang Z, Li N, Qiu F, Xu Z, Yan D, Yang S, Jia J, Kong X, Wei Z, Lu S, Lian L, Wu C, Wang $\mathrm{X}, \mathrm{Li} \mathrm{G}, \mathrm{Ma} \mathrm{T}$, et al. Whole-genome sequencing of six dog breeds from continuous altitudes reveals adaptation to high-altitude hypoxia. Genome Res. 2014; 24: 1308-1315

52. Ohtsuka T, Gilbert RD. Cardiac enzyme activities in fetal and adult pregnant and nonpregnant sheep exposed to high-altitude hypoxemia. J. Appl. Physiol. 1995; 79: 1286-1289.

\section{Tables}

Table 1. Sampling information for the 15 indigenous Tibetan sheep populations used in this study 


\begin{tabular}{|c|c|c|c|c|c|}
\hline Population & $\begin{array}{l}\text { population } \\
\text { code }\end{array}$ & $\begin{array}{l}\text { Sample } \\
\text { number }\end{array}$ & $\begin{array}{l}\text { Altitude } \\
\text { (m) }\end{array}$ & $\begin{array}{c}\text { Longitude } \\
\text { and } \\
\text { latitude }\end{array}$ & Sampling location \\
\hline $\begin{array}{l}\text { Guide Black Fur } \\
\text { sheep }\end{array}$ & GD & 39 & 3100 & $\begin{array}{l}\mathrm{N}: 38^{\circ} 61^{\prime} 152^{\prime \prime} \\
\mathrm{E}: 103^{\circ} 32^{\prime} 160^{\prime \prime}\end{array}$ & $\begin{array}{l}\text { Senduo Town, Guinan County, Hainan Tibetan Autonomous } \\
\text { State, Qinghai Province }\end{array}$ \\
\hline $\begin{array}{l}\text { Qilian White } \\
\text { Tibetan sheep }\end{array}$ & QL & 44 & 3540 & $\begin{array}{l}N: 42^{\circ} 20^{\prime} 178^{\prime \prime} \\
E: 116^{\circ} 64^{\prime} 618^{\prime \prime}\end{array}$ & $\begin{array}{l}\text { Qilian Town, Qilian County, Delingha City, Mongolian } \\
\text { Autonomous State, Qinghai Province }\end{array}$ \\
\hline $\begin{array}{l}\text { Tianjun White } \\
\text { Tibetan sheep }\end{array}$ & $\mathrm{TJ}$ & 64 & 3217 & $\begin{array}{l}N: 42^{\circ} 18^{\prime} 158^{\prime \prime} \\
E: 116^{\circ} 42^{\prime} 210^{\prime \prime}\end{array}$ & $\begin{array}{l}\text { Shengge Countryside, Tianjun County, Delingha City, } \\
\text { Mongolian Autonomous State, Qinghai Province }\end{array}$ \\
\hline $\begin{array}{l}\text { Qinghai Oula } \\
\text { Tibetan sheep }\end{array}$ & $\mathrm{QH}$ & 44 & 3630 & $\begin{array}{l}N: 34^{\circ} 16^{\prime} 433^{\prime \prime} \\
E: 101^{\circ} 32^{\prime} 141^{\prime \prime}\end{array}$ & $\begin{array}{l}\text { Jianke Village, Kesheng Town, Henan Mongolian } \\
\text { Autonomous County, Qinghai Province }\end{array}$ \\
\hline $\begin{array}{l}\text { Minxian Black } \\
\text { Fur sheep }\end{array}$ & $M X$ & 67 & 3180 & $\begin{array}{l}N: 36^{\circ} 54^{\prime} 48^{\prime \prime} \\
E: 103^{\circ} 94^{\prime} 107^{\prime \prime}\end{array}$ & $\begin{array}{l}\text { Taizi Village, Qingshui Town, Minxian County, Dingxi City, } \\
\text { Gansu Province }\end{array}$ \\
\hline $\begin{array}{l}\text { Ganjia Tibetan } \\
\text { sheep }\end{array}$ & GJ & 58 & 3022 & $\begin{array}{l}\mathrm{N}: 35^{\circ} 32^{\prime} 49^{\prime \prime} \\
\mathrm{E}: 102^{\circ} 40^{\prime} 802^{\prime \prime}\end{array}$ & $\begin{array}{l}\text { Xike Village, Ganjia Town, Xiahe County, Gannan Tibetan } \\
\text { Autonomous State, Gansu Province }\end{array}$ \\
\hline $\begin{array}{l}\text { Qiaoke Tibetan } \\
\text { sheep }\end{array}$ & QK & 71 & 3410 & $\begin{array}{l}N: 35^{\circ} 42^{\prime} 106^{\prime \prime} \\
E: 102^{\circ} 42^{\prime} 210^{\prime \prime}\end{array}$ & $\begin{array}{l}\text { Waeryi Village, Qihama Town, Maqu County, Gannan Tibetan } \\
\text { Autonomous State, Gansu Province }\end{array}$ \\
\hline $\begin{array}{l}\text { Gannan Oula } \\
\text { Tibetan sheep }\end{array}$ & GN & 52 & 3616 & $\begin{array}{l}N: 33^{\circ} 51^{\prime} 312^{\prime \prime} \\
E: 101^{\circ} 52^{\prime} 424^{\prime \prime}\end{array}$ & $\begin{array}{l}\text { Daerqing Administrative Village, Oula Town, Maqu County, } \\
\text { Gannan Tibetan Autonomous State, Gansu Province }\end{array}$ \\
\hline $\begin{array}{l}\text { Langkazi Tibetan } \\
\text { sheep }\end{array}$ & LKZ & 10 & 4459 & $\begin{array}{l}N: 28^{\circ} 58^{\prime} 951^{\prime \prime} \\
E: 090^{\circ} 23^{\prime} 757^{\prime \prime}\end{array}$ & $\begin{array}{l}\text { Kexi Village, Langkazi Town, Langkazi County, Shannan } \\
\text { Territory of Tibet Autonomous Region }\end{array}$ \\
\hline $\begin{array}{l}\text { Jiangzi Tibetan } \\
\text { sheep }\end{array}$ & $J Z$ & 46 & 4398 & $\begin{array}{l}N: 28^{\circ} 55^{\prime} 113^{\prime \prime} \\
E: 089^{\circ} 47^{\prime} 692^{\prime \prime}\end{array}$ & $\begin{array}{l}\text { Reding Village, Cheren Town, Jiangzi County, Shannan } \\
\text { Territory of Tibet Autonomous Region }\end{array}$ \\
\hline $\begin{array}{l}\text { Gangba Tibetan } \\
\text { sheep }\end{array}$ & GB & 85 & 4403 & $\begin{array}{l}N: 28^{\circ} 15^{\prime} 281^{\prime \prime} \\
E: 088^{\circ} 24^{\prime} 787^{\prime \prime}\end{array}$ & $\begin{array}{l}\text { Yulie Village, Gangba Town, Gangba County, Rikaze Territory } \\
\text { of Tibet Autonomous Region }\end{array}$ \\
\hline $\begin{array}{l}\text { Huoba Tibetan } \\
\text { sheep }\end{array}$ & $\mathrm{HB}$ & 34 & 4614 & $\begin{array}{l}\mathrm{N}: 30^{\circ} 13^{\prime} 822^{\prime \prime} \\
\mathrm{E}: 083^{\circ} 00^{\prime} 249^{\prime \prime}\end{array}$ & $\begin{array}{l}\text { Rima Village, Huoba Town, Zhongba County, Rikaze Territory } \\
\text { of Tibet Autonomous Region }\end{array}$ \\
\hline $\begin{array}{l}\text { Duoma Tibetan } \\
\text { sheep }\end{array}$ & DM & 8 & 4780 & $\begin{array}{l}N: 29^{\circ} 48^{\prime} 609^{\prime \prime} \\
E: 091^{\circ} 36^{\prime} 191^{\prime \prime}\end{array}$ & $\begin{array}{l}\text { Sixth Village, Maqu Town, Anduo County, Naqu Territory of } \\
\text { Tibet Autonomous Region }\end{array}$ \\
\hline $\begin{array}{l}\text { Awang Tibetan } \\
\text { sheep }\end{array}$ & AW & 5 & 4643 & $\begin{array}{l}N: 30^{\circ} 12^{\prime} 101^{\prime \prime} \\
E: 098^{\circ} 63^{\prime} 098^{\prime \prime}\end{array}$ & $\begin{array}{l}\text { Ayi Third Village, Awang Town, Gongjue County, Changdou } \\
\text { Territory of Tibet Autonomous Region }\end{array}$ \\
\hline $\begin{array}{l}\text { Linzhou Tibetan } \\
\text { sheep }\end{array}$ & LZ & 9 & 4292 & $\begin{array}{l}N: 29^{\circ} 09^{\prime} 121^{\prime \prime} \\
E: 091^{\circ} 25^{\prime} 063^{\prime \prime}\end{array}$ & $\begin{array}{l}\text { Tanggu Village, Tanggu Town, Linzhou County, Tibet } \\
\text { Autonomous Region }\end{array}$ \\
\hline
\end{tabular}

Table 2 Criterion of indigenous Tibetan sheep populations classified for different factors 


\begin{tabular}{|c|c|c|}
\hline Types & Parameters & Subpopulation \\
\hline Altitude & $<3500 \mathrm{~m}$ & 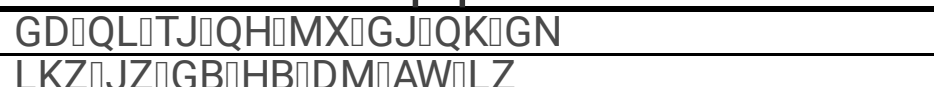 \\
\hline \multirow[t]{2}{*}{ Coat coloration } & Black & MX口GD \\
\hline & White & 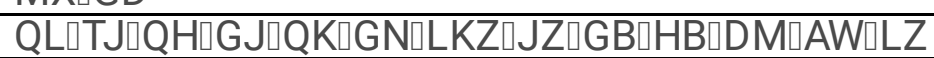 \\
\hline \multirow[t]{2}{*}{ Geographic locations } & Qinghai & GDLQLDTJ \\
\hline & $\begin{array}{l}\text { Gansu } \\
\text { Tibetan }\end{array}$ & 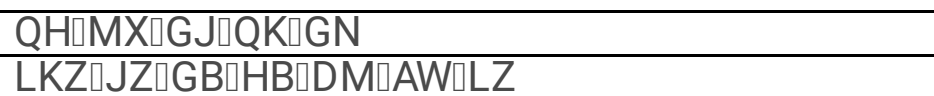 \\
\hline
\end{tabular}

\section{Figures}

A

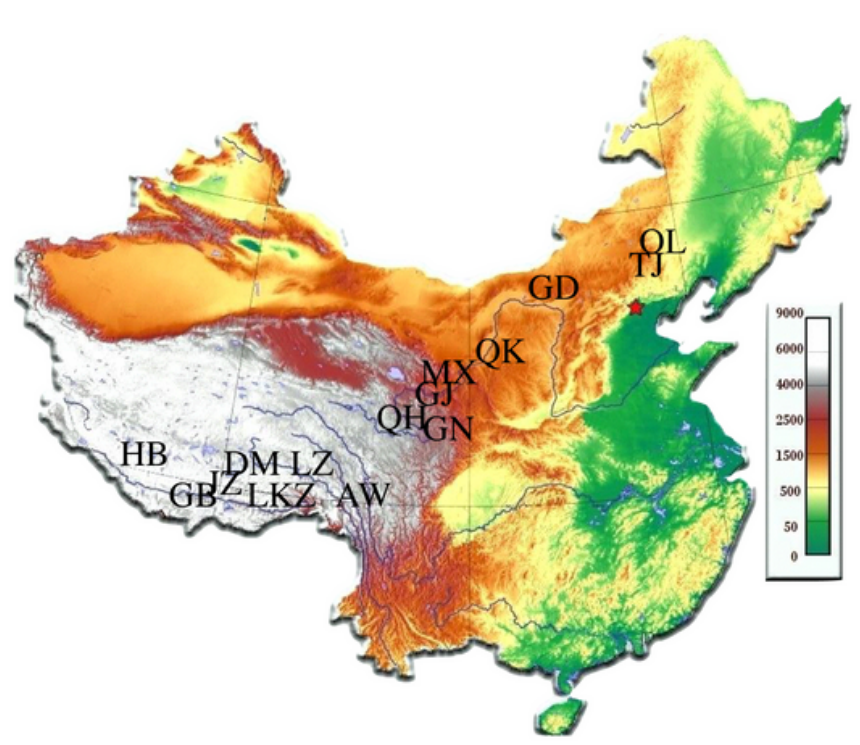

C

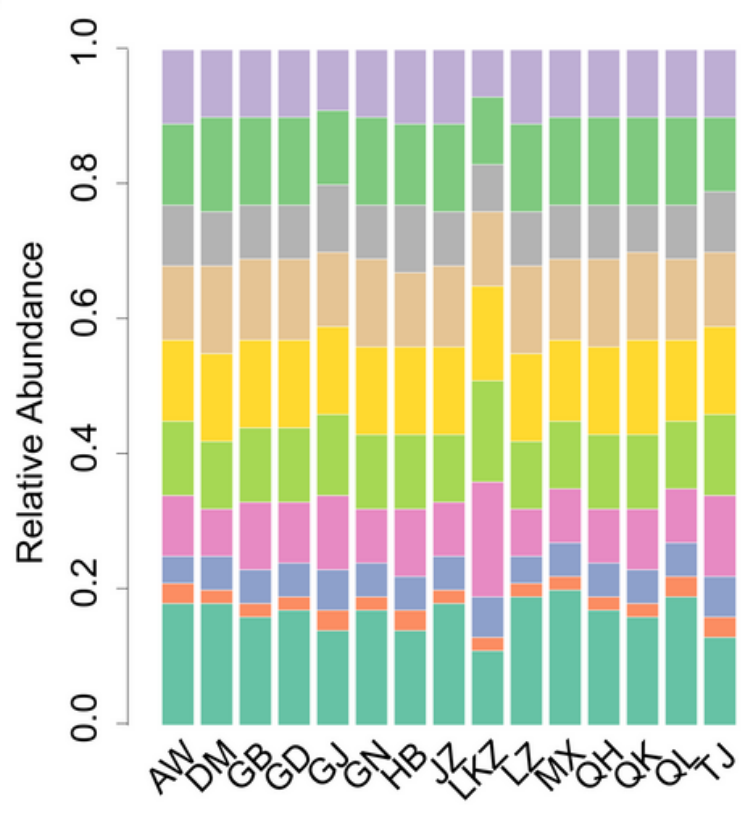

B

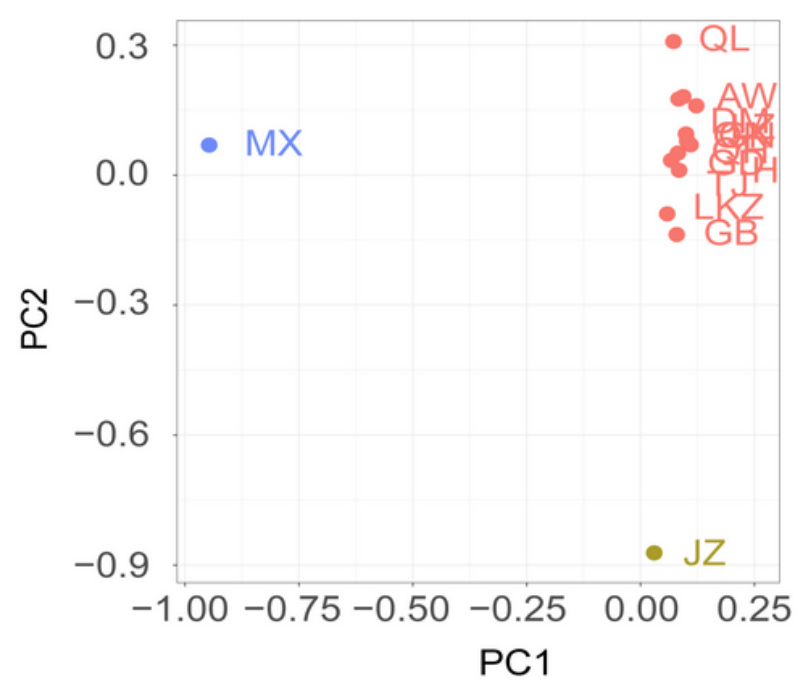

D
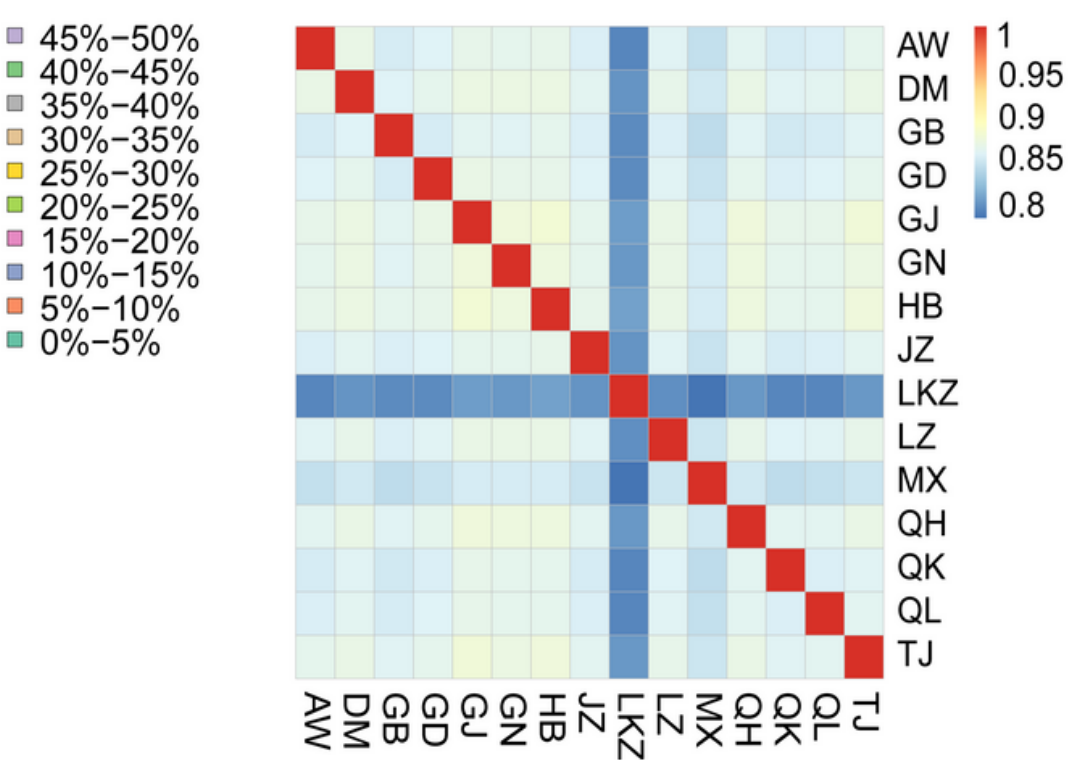


\section{Figure 1}

SNP analysis and population structure for 15 indigenous Tibetan sheep populations. A: distributive map of 15 indigenous Tibetan sheep populations living in the Qinghai-Tibetan Plateau areas in China used in this study; B: Principal component analysis on whole genomic DNA sequencing in different Tibetan sheep populations; c: Distribution of minor allelic frequency (MAF) with 10 continued classes from 0-0.05 to 0.45-0.50; D: Relatedness of similarity index (IS) values in 15 Tibetan sheep populations. Note: The designations employed and the presentation of the material on this map do not imply the expression of any opinion whatsoever on the part of Research Square concerning the legal status of any country, territory, city or area or of its authorities, or concerning the delimitation of its frontiers or boundaries. This map has been provided by the authors. 
A

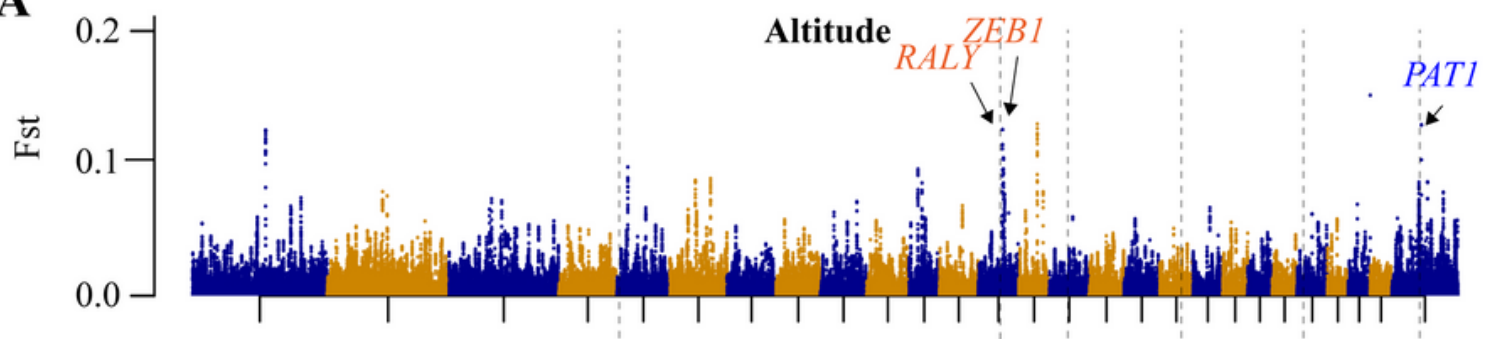

B
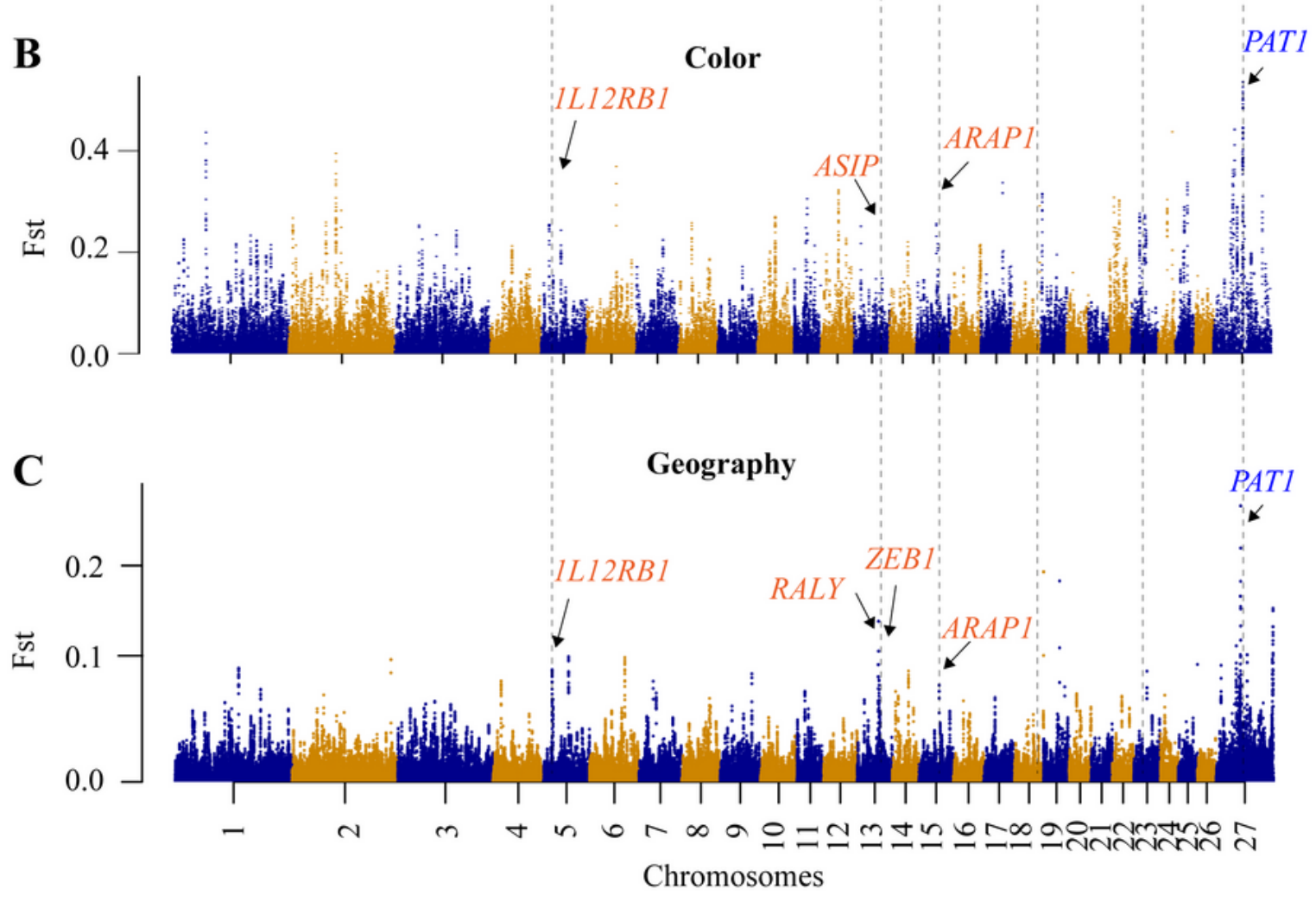

D

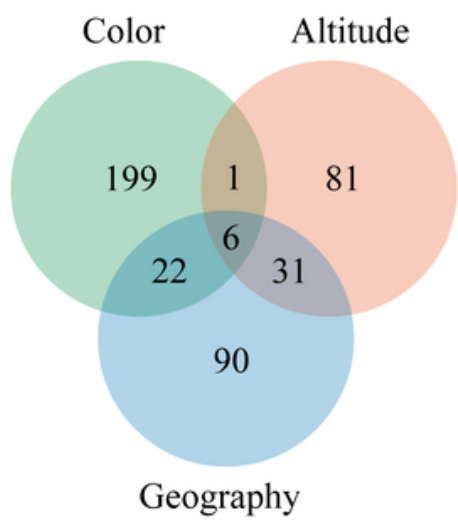

$\mathbf{E}$

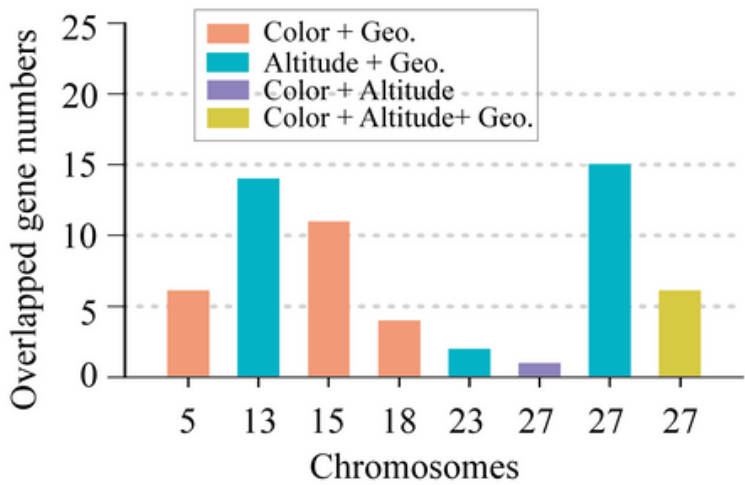

Figure 2

Manhattan analysis and candidate genes exploration. A-C: Manhattan plot representing Fst values for each SNP across Chromosomes for three clustered subpopulations. The overlapped genes were highlighted in blue fonts. Identified genes in two and three clusters were labeled in yellow and blue, respectively. D: Venn diagram representing overlapped genes across different clustered subpopulations. 
E: Numbers of corresponding genes harboring overlapped SNPs across different clustered subpopulations.

A

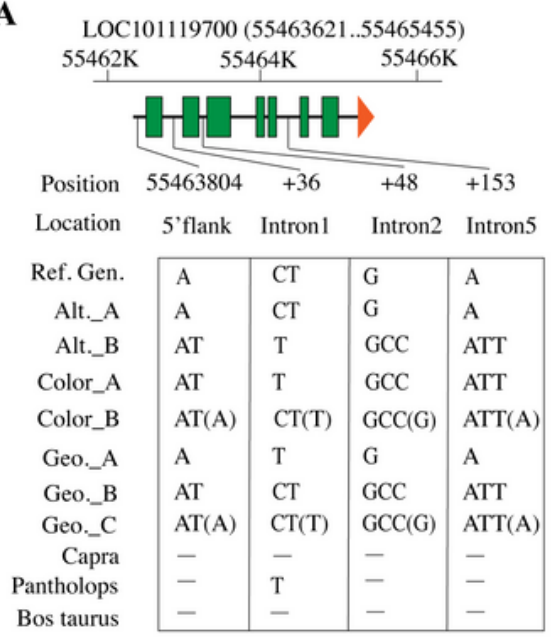

C

\begin{tabular}{|c|c|c|c|c|}
\hline \multicolumn{5}{|c|}{ PAT1 (72792299..72795221) } \\
\hline \multicolumn{5}{|c|}{$\begin{array}{lll}72792 K & 72794 K & 72796 K\end{array}$} \\
\hline Position & 72792241 & +82 & +1492 & +3109 \\
\hline Location & 5'UTR & Intron 1 & Intron4 & 3'Flank \\
\hline Ref. Gen. & $\mathrm{CA}$ & TA & $\mathrm{C}$ & G \\
\hline Alt._A & $\mathrm{CA}$ & TA & CAA & GT \\
\hline Alt._B & $\mathrm{C}$ & $\mathrm{TA}$ & CAA & GT \\
\hline Color_A & $\mathrm{C}$ & $\mathrm{T}$ & CAT & GT \\
\hline Color_B & $\mathrm{CA}$ & $\mathrm{TA}(\mathrm{T})$ & $\mathrm{CAA}(\mathrm{C})$ & GT(G) \\
\hline Geo._A & $\mathrm{CA}$ & TA & $\mathrm{C}$ & G \\
\hline Geo._B & $\mathrm{C}$ & $\mathrm{T}$ & CAA & GT \\
\hline Geo._C & $\mathrm{CA}$ & $\mathrm{TA}(\mathrm{T})$ & $\mathrm{CAA}(\mathrm{C})$ & $\mathrm{GT}(\mathrm{G})$ \\
\hline Capra & - & - & - & - \\
\hline Pantholops & $\mathrm{C}$ & - & - & GT \\
\hline Bos taurus & - & - & - & - \\
\hline
\end{tabular}

$\mathbf{E}$

\begin{tabular}{rl|l|}
\multicolumn{3}{c}{ APOOL (72757514..72892083) } \\
\multicolumn{1}{c}{ A2750K } & \multicolumn{2}{c}{$72850 \mathrm{~K}$} \\
Position & 72813200 & +973 \\
Location & Intron2 & Intron8 \\
Ref.Gen. & C & ATT \\
Alt._A & CG & A \\
Alt._B & C & A \\
Color_A & CG & ATT \\
Color_B & GG(C) & ATT(A) \\
Geo._A & C & ATTG \\
Geo._B & CG & A \\
Geo._C & CG(C) & ATT(A) \\
Capra & - & - \\
Pantholops & - & - \\
Bos taurus & - & - \\
\cline { 2 - 3 }
\end{tabular}

B

\begin{tabular}{|c|c|c|c|}
\hline $56043 \mathrm{~K}$ & \multicolumn{2}{|c|}{$56045 \mathrm{~K}$} & $56047 \mathrm{~K}$ \\
\hline Position & 56044885 & +124 & +333 \\
\hline Location & Intron I & Exton2 & Intron2 \\
\hline Ref. Gen. & CGG & A & $\mathrm{TC}$ \\
\hline Alt._A & $\mathrm{C}$ & $\mathrm{AC}$ & $\mathrm{T}$ \\
\hline Alt._B & CGG & A & $\mathrm{TC}$ \\
\hline Color_A & CGG & A & $\mathrm{TC}$ \\
\hline Color_B & $\mathrm{CGG}(\mathrm{C})$ & $\mathrm{AC}(\mathrm{A})$ & $\mathrm{TC}(\mathrm{T})$ \\
\hline Geo._A & $\mathrm{C}$ & $\mathrm{AC}$ & $\mathrm{T}$ \\
\hline Geo._B & $\mathrm{CGG}(\mathrm{C})$ & $\mathrm{AC}(\mathrm{A})$ & $\mathrm{TC}(\mathrm{T})$ \\
\hline Geo._C & $\mathrm{CGG}(\mathrm{C})$ & $\mathrm{AC}(\mathrm{A})$ & $\mathrm{TC}(\mathrm{T})$ \\
\hline Capra & CGG & - & - \\
\hline Pantholops & - & - & - \\
\hline Bos taurus & - & - & - \\
\hline
\end{tabular}

D ZNF711 (72993669..73020595)

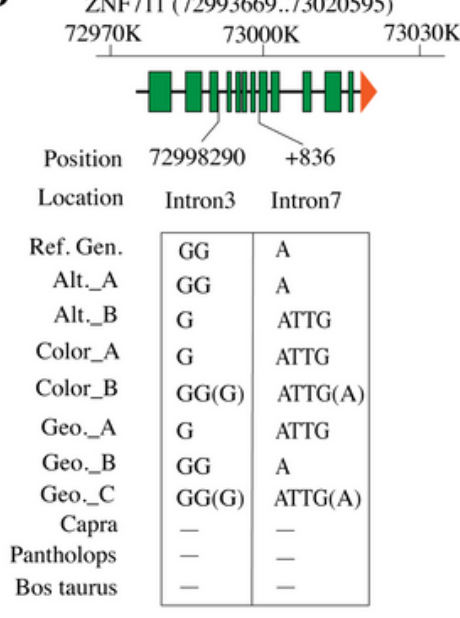

F

\begin{tabular}{|c|c|c|c|}
\hline \multicolumn{4}{|c|}{ POF1B (73024346..73123532) } \\
\hline $73000 \mathrm{~K}$ & 731 & $\mathrm{OOK}$ & $73200 \mathrm{~K}$ \\
\hline Position & 73063200 & +614 & +1390 \\
\hline Location & Intron4 & Intron7 & Exton 10 \\
\hline Ref. Gen. & A & GG & CTT \\
\hline Alt._A & AT & $\mathrm{G}$ & $\mathrm{C}$ \\
\hline Alt._B & A & GG & CTT \\
\hline Color_A & A & $\mathrm{G}$ & $\mathrm{C}$ \\
\hline Color_B & $\mathrm{AT}(\mathrm{A})$ & $\mathrm{GG}(\mathrm{G})$ & CTT(C) \\
\hline Geo._A & A & GG & CTT \\
\hline Geo,_B & AT & G & $\mathrm{C}$ \\
\hline Geo._C & $\mathrm{AT}(\mathrm{A})$ & $\mathrm{GG}(\mathrm{G})$ & CTT(C) \\
\hline Capra & - & - & - \\
\hline Pantholops & - & - & - \\
\hline Bos taurus & - & - & - \\
\hline
\end{tabular}

Figure 3

Gene INDEL analysis for 4 candidate overlapped genes. A-D: INDEL analysis on KLF4, PSMA1, PAT1, and ZNF711 genes within clustered subpopulations in addition to three other species including Capra, Pantholops, and Bos taurus. 
PAT1 Secondary structure

1

III

$* * * * * * *$
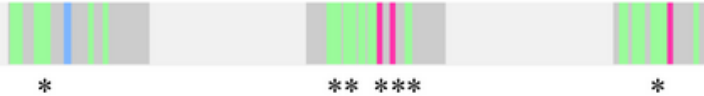

|| Helix | Turn || Beta strand || PDB Structure known for this area

PAT1 MSFDPNLLHNNGHNGYPSGTSAALRETGIVEKLLTSYGFIOCSERQARLFFHCSOYYGNL

CSDE1 MSFDPNLLHNNGHNGYPNGTSAALRETGVIEKLLTSYGF IQCSERQARLFFHCSQYNGNL $* * * * * * * * * * * * * * * * *, * * * * * * * * * *:: * * * * * * * * * * * * * * * * * * * * * * * * * * \quad * * *$

PAT1 QDLKVGDDVEFEVSSDRRTGKPIAVKLVKRKQEILPEERINGQEVFYLSYTPEDVEGNVQ

CSDE1 QDLKVGDDVEFEVSSDRRTGKPIAVKLVKIKQEILPEERINGQEVFYLTYTPEDVEGNVQ $* * * * * * * * * * * * * * * * * * * * * * * * * * * * * \quad * * * * * * * * * * * * * * * * * *: * * * * * * * * * * *$

60

60

120

PAT1 LETGDKINFVIDNNKHTGAVSARNIMLLKKKQARYQGVVCAMKEAFGFIERGDIVKEIFF

CSDE1 LETGDKINFVIDNNKHTGAVSARNIMLLKKKQARYQGVVCAMKEAFGF IERGDIVKEIFF

PAT1 HYSEFKGDLESLQPGDDVEFTVKDRNGKEVATDVRLLPQGTVIFEDISIEHFEGTVTKVI

CSDE1 HYSEFKGDLESLQPGDDVEFTIKDRNGKEVATDVRLLPQGTVIFEDISIEHFEGTVTKVI $* * * * * * * * * * * * * * * * * * * * * ; * * * * * * * * * * * * * * * * * * * * * * * * * * * * * * * * * * * * * *$

B

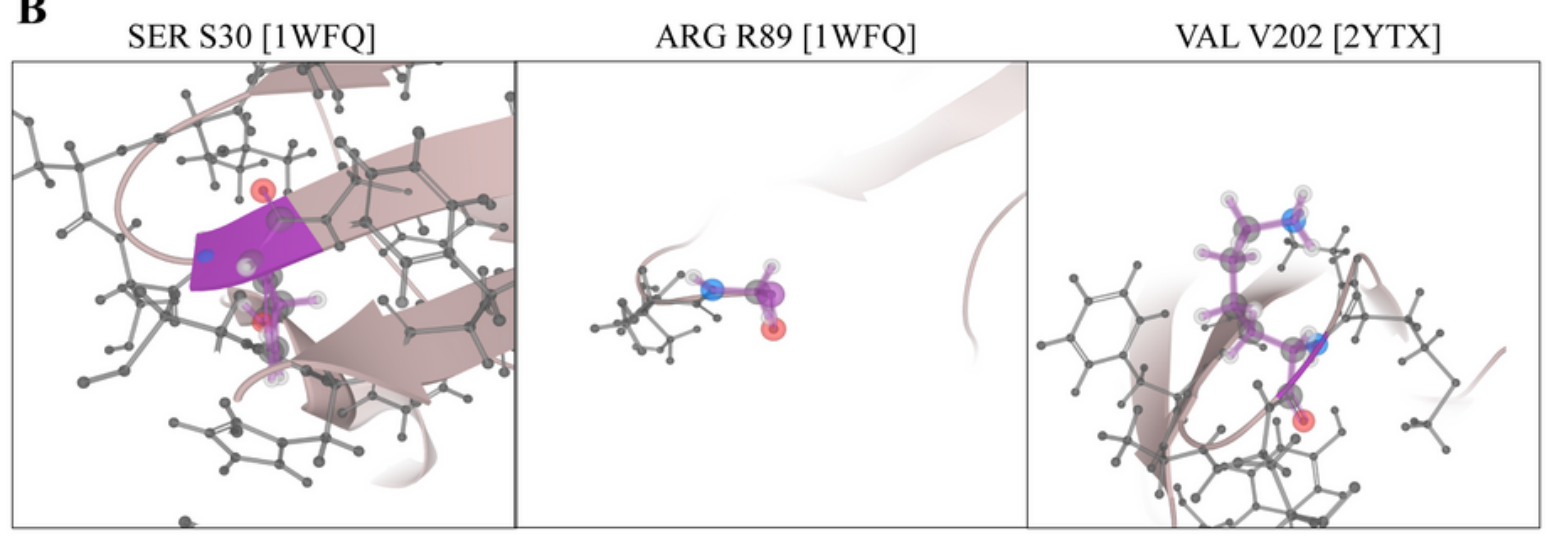

C

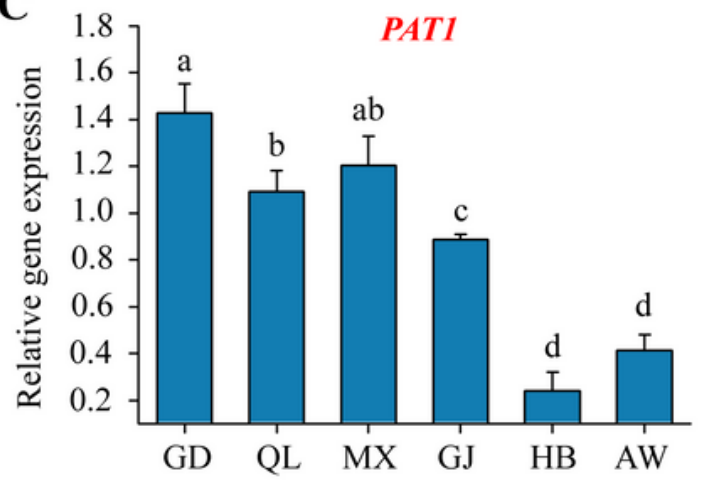

$\begin{array}{llllllll}\text { Altitude } & \mathrm{H} & \mathrm{H} & \mathrm{H} & \mathrm{H} & \mathrm{L} & \mathrm{L}\end{array}$

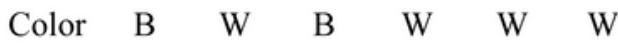

Region QH $\quad$ QH $\quad$ GS $\quad$ GS $\quad$ XZ $\quad$ XZ
D

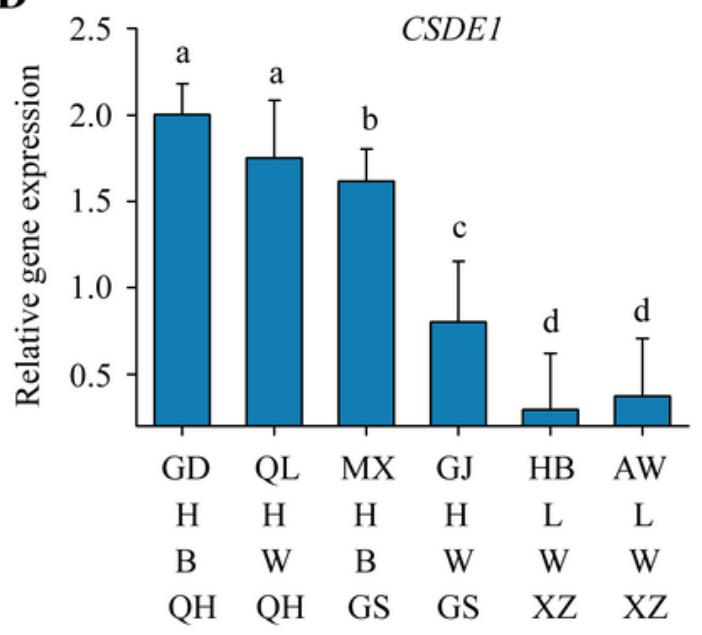

Figure 4

Comparison on sequence alignments and expression pattern between PAT1 and CSDE1. A: Secondary structure of PAT1 and differentiated amino acids between PAT1 and CSDE1. The location of 7 differentiated amino acids were depicted in symbol "*”, which are majorly on beta-strand and turn. Secondary structure of protein is predicted via Uniprot database from different PDB entries. B: Differentiated location of amino acids on representative 3D protein structure; C-D: Comparison on 
expression of CSDE1 and PAT1 in given 6 indigenous Tibetan sheep populations in this study. The 6 indigenous Tibetan sheep populations include Guide Black Fur sheep (GD), Qilian White Tibetan sheep (QL), Minxian Black Fur sheep (MX), Ganjia Tibetan sheep (GJ), Huoba Tibetan sheep (HB) and Awang Tibetan sheep (AW). Expression values were calculated against GAPDH using mRNA in lungs, and four biological replicates were conducted.

\section{Figure 5}

Comparison on morphological and physiological traits in Tibetan sheep populations with different haplotype promoters of PAT1 gene. A: Representative picture of indigenous Tibetan sheep (Huoba Tibetan sheep, HB for C-type, and Guide Black Fur sheep, GD for CA type) originated between two haplotypes promoter of PAT1; B: Comparison on different physiological parameters of 15 Tibetan sheep between CA and C haplotype of PAT1. CA type include GJ and QL, while C type include AW and HB. The averaged values for each parameter was derived from at least 10 biological replicates.

\section{Supplementary Files}

This is a list of supplementary files associated with this preprint. Click to download.

- SupplementalFigures.docx

- SupplementaryTables.xls 